\title{
Family Communication in Rural and Slum Regions of Kenya
}

\section{Erick Oduor}

School of Interactive Arts +

Technology

Simon Fraser University

$250-13450102^{\text {nd }}$ Avenue

Surrey, BC, Canada, V3T 0A3

eoduor@sfu.ca

\section{Carman Neustaedter}

School of Interactive Arts +

Technology

Simon Fraser University

$250-13450102^{\text {nd }}$ Avenue

Surrey, BC, Canada, V3T 0A3

carman_neustaedter@sfu.ca

\section{Serena Hillman}

School of Interactive Arts +

Technology

Simon Fraser University

250 - $13450102^{\text {nd }}$ Avenue

Surrey, BC, Canada, V3T OA3

shillman@sfu.ca

\section{Carolyn Pang}

School of Interactive Arts +

Technology

Simon Fraser University

250 - $13450102^{\text {nd }}$ Avenue

Surrey, BC, Canada, V3T 0A3

carolyn_pang@sfu.ca

\begin{abstract}
We report the findings of an ethnographic study exploring how 13 participants from rural and slum regions of Kenya communicated with remote family members using technology. We focus on communication practices that enabled family members to support economic sustenance activities and also investigate the social aspects of using technology to provide or receive moral, emotional or other forms of support from distributed family members.
\end{abstract}

\section{ACM Classification Keywords}

Technology and developing countries, HCI4D

\section{Author Keywords}

H.5.m. Information interfaces and presentation (e.g., HCI): Miscellaneous.

\section{Introduction}

Family members have a natural desire to stay in touch with one another when separated by distance $[11,18]$. This allows them to coordinate shared activities and feel close and connected to one another [4, 11]. A variety of systems have been designed to support family communication and sharing of activities [11], photo-sharing applications [1], and messaging systems [3]. However, these studies focused on designing systems for families in developed countries. Turning to 
developing countries like Kenya, Africa, we see there is less research focused on uncovering family routines for communication and the need for new technologies.

To address this, we focus on exploring how people in the developing country of Kenya communicate with their distributed family members, both within the country and abroad, and what challenges they face. Our goal is to understand how poverty, limited technology infrastructure, and low literacy levels $[5,6]$ affect the choice of technology for use in coordinating collaborative family activities in rural and selected slum parts of Kenya.

\section{Related Work}

Various studies have suggested understanding the dynamics and needs of local communities in developing countries before designing technology for use in these regions. Taylor et al encourage fieldwork ethnographers $[9,17]$ to look beyond networks that have been defined within $\mathrm{HCI}$ fields from the perspectives of the western cultures to understand ICTD [17].

In this realm, we see several studies that are complementary to our work. Rangaswamy and Sambisvan investigated how the diversity of low income communities in Indian slums promoted surrogate technology use by technology savvy family members who showed computer illiterate relatives how to use the technology [14]. Liu et al provides a model for technology acceptance where they explain that designing technology that resonates with the social values of a local community will have high acceptance ability with the intended users [7]. Wyche et. al investigated how professionals living in Nairobi, Kenya used technology in a constrained setting by engaging in planned and meaningful offline preparation before accessing the Internet [19].

Our work builds on this research by describing results of a study that investigates the challenges facing individuals who use technology to coordinate family activities in developing countries. Our findings also highlight the opportunities for the design of collaborative systems that can support the sharing of family activities to promote connectedness in rural and slum regions of developing countries.

\section{Study Methodology}

We conducted a study with 13 people from Kenya, Africa with the goal of understanding their family communication practices.

\section{Participants and Sites}

Nine participants ( 6 women and 3 men) were recruited from Awendo, Kenya which lies 360 km from the capital city of Nairobi. It is a rural part of the Migori District, which has a population of 46,576 [8]. Seven of our participants from this region practiced various sorts of subsistence farming and small-scale business activities such as selling fish by the road side. Four participants were selected from Githurai [2] which is a mixture of slums and suburbs and lies in the eastern part of Nairobi. With a population of over 300,000 people, $47 \%$ of its inhabitants live below the 'poverty line' [12]. Twelve of our thirteen participants were recruited through snowball sampling and one participant was recruited using a Facebook post.

\section{Interview Method}

We conducted semi-structured interviews where participants were asked a series of questions about how 
they communicated with remote family who were distributed across the country and abroad. We focused on situations where they shared information on family activities. For example, we asked questions such as: which family members do you most frequently communicate with?, what technology do you use (if any) during communication?; and what challenges do you face in communicating with these individuals? Interviews lasted 45 to 60 minutes.

\section{Data Collection and Analysis}

We audio-recorded all interviews and kept handwritten notes. We also captured photos of participant's' homes and areas of communication. The audio data was later transcribed. Open coding was used to identify salient themes within the audio. Initial themes were identified gradually in a manner of convergence, and then the rest of the data was coded iteratively based on the initial themes to relate the communication practices to the activity sharing they supported best. The data was also analyzed by creating affinity diagrams using a bottom-up inductive approach. Commonalities and themes relating to communication practices and technology use were then extracted from the affinity diagrams [16].

\section{Results}

Our studies reveal that the choice of technology for communicating with family members depended on an individual's knowledge in using or accessing technology and the type of activities that provided a common basis for sharing. We outline several of the primary situations that we found in the following subsections.

\section{Sustenance and Subsistence Practices}

First, seven of our rural participants engaged with subsistence farming activities in conjunction with their relatives who worked in the city yet owned small farming land in the village. As descriptive cases, we describe two participants from our study as representative examples.

First, P7, a rural participant, mainly used his mobile phone to coordinate and share information about his farming activities. He occasionally called his sister who worked in Migori to provide updates on sugarcane weeding that was ongoing in the village. P7 would describe how they have used the fertilizer that was previously bought, and seek for money to pay two farm helps whenever there was extra work on the farm. The sister would ask P7 how many rows of sugar cane had been weeded so far to determine how much work was left before she calculated the amount of money that she needed to remit to him through his mobile phone. They would then discuss the amount of work that was going to be completed before further finances would be required. P7 would make brief one minute phone calls in the evenings asking the sister to call back. Once the sister called back, they would engage in these discussions.

Second, P13 used his mobile phone while conducting his motorcycle taxi duties to run small errands for his family members who lived in the village. He normally drove between his home and a local shopping center about $20 \mathrm{~km}$ away. This situation was different than P7 because the participant lived within the same village or homestead as the family members he was calling. P7 would receive calls or text messages from his wife, mother or siblings who lived in the village. They would 
ask him to buy small commodities such as bathing soap or sugar packs on his way back from work. Once he received these messages, he would go ahead and purchase the commodity requested and bring it home. If P13 was dropping a customer close to his house early in the day, he would call the person who requested the commodity and ask them to send a child by the roadside to pick the commodity as he continued with his work. If it was any time after $5 \mathrm{pm}$ in the evening, he would bring the commodity back with him on his last trip. P13 would be reached by phone or text messaging any time during the day since he always had his phone ready in case a customer called for taxi services.

\section{Family Support Structures}

Second, some participants used technology to provide moral support and guidance for their distributed family members. Here we describe the situations faced by two of our participants, P3 (slum) and P6 (rural), in this regard.

We begin with P3 who was a civil servant earning a monthly salary of $\$ 200$ and living with his wife and eight kids in the slums of Githurai. P3 had a large extended family that included his siblings' widows and their children who he provided with guidance and moral support. As the sole remaining man in his father's homestead, he had a cultural obligation to monitor how his late brothers' widows were faring. Because of his low income, he was not able to provide financial assistance to his extended family. Instead, he would occasionally call them to listen to their issues. This typically occurred after his rural family members had sent a message asking him to call them back. In most situations, this was because a situation out-of-theordinary occurred such as a child being sent away from school for disciplinary issues. P3 would purchase mobile phone credits to make these calls. Calls were made after $8 \mathrm{pm}$ when he was well rested from work and already engaged in face-to-face discussion with his own children. Even though the phone credit was not enough to allow for communication with all his extended relatives in the village, he would let the widows of his siblings talk on behalf of their children. Thus, we see an example of information being passed along between family members such that P3 only needed to talk with a small number of individuals in order to understand how everyone was doing. Beyond using mobile phones, P3 explained that he did not see the importance of using the computer since there were more pressing issues such as providing for his family than learning how to use a computer. He also mentioned that if he had been economically empowered, he would have wished to call his extended relatives more to monitor their progress with education, or small business activities more closely. Currently that was not possible based on his meager earnings.

Our next participant, P6, was a retired teacher who was a church elder and also engaged in dairy farming in his rural home. He mainly used his mobile phone to communicate with his children, his siblings and other family members who lived in the city and other parts of the country. Three of his children worked in Nairobi while two lived abroad. He mainly called his children who lived in Kenya in the evenings after they had got back home from work. He would call them after 10 pm since there was a promotion during which a minute's call would cost only one Shilling. Here he would offer fellowship for his children and their families, while also providing them with parental guidance to ensure stronger family units. On the other hand, P6 would only 
talk to the two children who lived outside of Kenya when they called him. This placed the onus of paying for the calls on his children. They would call at least once a week to keep in touch with their parents unless P6 had sent them a text message asking them to call back immediately. This occurred in situations where they were required to provide financial support for their distant relatives who were attending college. P6 owned two PCs that were kept in the storage because he did not have the knowledge or interest in using them.

Technology Accessibility and Types of Users Thirdly, we explain how some participants used technologies beyond mobile phone calling because they were actually more affordable or more convenient.

For example, P4 was a participant from the slums and even though he lived in a very poor area, he was computer literate and had experience with sending emails, browsing the Internet and even using Facebook. He accessed the Internet daily from a cyber café since he could not afford to purchase his own computer. As the eldest in his family, he was culturally obligated to occasionally update his siblings who lived in the USA on family issues from their rural home that needed their attention, such as financial assistance.

Emails and Facebook chat were the only cheap communication means available to him. If the information to be passed did not require immediate response, then he would send an email to his siblings, otherwise he would send a Facebook message and ask his siblings to come to Facebook chat so that they could share the information. P4 used the internet for international communication since it was affordable to pay for Internet at Kshs 40 (\$0.50) per hour compared to calling which he could simply not afford.
P8 who lived in the village and had no formal secondary school education, asked her children to set up her voice mail so that she could receive audio messages

whenever her phone was turned off. This way she could conserve the phone's battery, but still receive on

financial assistance from her uncle. This practice is in line with Smyth et al who explain that technology "bumps" cannot hinder a user from serving his/her intended purpose if one is already willing to get a service from the technology [15].

\section{Discussion}

We are continuing to analyze results from our ethnographic study. Some of the problems that potential technology users in developing countries experience such as a lack of knowledge to use computers, or limited technology infrastructure have also been reported elsewhere. Sambisvan et al reported how illiterate technology users accessed entertainment through mediation by technology savvy relatives in Indian slums [14]. We found that poor rural participants used mediation of technology to seek financial support from their distributed family for basic needs such school fees payment and not entertainment.

Designers should think beyond current available user limitations while designing ICT4D applications. This is because technology that resonates with the cultural practices of local communities will possibly be embraced in the future. Smyth et al found that communities in developing countries are capable of embracing advanced information technologies if the appropriate motivation exists while investigating the sharing and consumption of entertainment media on low cost mobile phones in urban India [15]. Our 
investigations reveal how a poor slum participant from Githurai was able to share important family information with remote members living abroad using Email and Facebook since he could not afford to make international calls. Here, the strong desire for family connection resulted in the participant's use of social media for connection rather than entertainment.

\section{Conclusion}

We have gathered observations that form the basis for further research in the area of designing technology applications that will allow family members in rural and slum communities of developing countries such as Kenya to connect with their remotely distributed families over shared cultural activities.

\section{References}

[1] Burrel, J and Toyama, K. (2009). What Constitutes Good ICT Research? Annerberg School of Communication

[2] Githurai Community A Kenyatta University-Githurai Partnership http://www.ku.ac.ke/Githurai/index.html

[3] Hindus, D., Mainwaring, S. D., Leduc, N., Hagström, A. E., and Bayley, O. (2001). Casablanca: Designing social communication devices for the home, Proc. CHI, ACM Press (2001), 325-332.

[4] Judge, T.K., Neustaedter, C., and Kurtz, A.F. (2010). The Family Window: The Design and Evaluation of a Domestic Media Space. Proc. CHI, ACM Press

[5] Kam, M., Mathur, A., Kumar, A., and Canny, J. (2009). Designing Digital Games for Rural Children: A study of Traditional Village Games in India. Proc. CHI, Boston, MA. ACM Press.

[6] Kow, Y., Wen, J., Chen, Y. (2012) Designing Online Games for Real-life Relationships: Examining $Q Q$ Farm in Intergenerational Play. Proc. CSCW, ACM Press.
[7] Liu, J., Liu, Ying., Rau, P., Li, Hui., Wang, X., Li, D. (2010).How Socio-Economic Structure Influences Rural Users' Acceptance of Mobile Entertainment, Proc. CHI, ACM Press.

[8] MigoriTown.com http://migoritown.com/

[9] Millen, D. (2000) Rapid Ethnography: Time Deepening Strategies for HCI Field Research. Proc. DIS ACM Press.

[10] M-Pesa: Kenya's mobile wallet revolution http://www.bbc.co.uk/news/business-11793290

[11] Neustaedter, C., Elliot, K., and Greenberg, S., (2006). Interpersonal Awareness in the Domestic Realm, Proc. OzCHI, ACM Press.

[12] Poverty Overview

http://www.worldbank.org/en/topic/poverty/overview

[13] Rangaswamy, M. and Sambasivan, N. (2011).

Cutting Chaai, Jugaad and Here Pheri: towards

UbiComp for a global community.

[14] Sambisvan, N., Cutrell, E., Toyama, K., and Nardi, B. (2010). Intermediated Technology Use in Developing Communities. Proc. CHI, ACM Press.

[15] Smyth, T., Kumar, S., Medhi, I. and Toyama, K. (2010) Where There's a Will There's a Way: Mobile Media Sharing in Urban India, Proc. CHI, ACM Press.

[16] Strauss, A.C. and Corbin, J. (1998) Basics of Qualitative Research, Sage Publications.

[17] Taylor, A. (2011) Out There. Proc. CHI, ACM Press.

[18] Tee, K., Brush, A.J.B. and Inkpen, K.M., (2009) "Exploring Communication and Sharing Between Extended Families," International Journal of HumanComputer Studies 67, 2, 128-138.

[19] Wyche, S.P., Smyth, T.N., Chetty, M., Aoki, P.M. and Grinter, R.E., (2010) "Deliberate Interactions: Characterizing Technology Use in Nairobi, Kenya," Proc. CHI, ACM Press, 2593-2602. 